\title{
Plasma fibroblast growth factor-23 level and its relation to carotid artery atherosclerosis in hemodialysis patients
}

\begin{abstract}
Background: Abnormalities in bone metabolism are a prevalent condition in CKD patients. FGF23 has been suggested to play a role in vascular calcification in patients on regular hemodialysis (HD).
\end{abstract}

Objective: This work was carried out to evaluate the prevalence of carotid artery atherosclerosis in patients with end stage renal disease (ESRD) on regular haemodialysis and the role of FGF-23 in this event.

Subject and methods: A total number of 50 patients aged over 18 years and on regular haemodialysis for one or more years were included in this study. Intact FGF-23 and other laboratory parameters were measured by specific methods for all patients; Also Duplex scan of the carotid arteries was performed to assess carotid intima-media thickness (CIMT) by high-resolution real-time B mode ultrasonography.

Results: Serum phosphorus, CIMT, LDL, There found to be significantly high with increasing FGF 23 levels (pis 0.005, 0.001, 0.02 and 0.001 respectively). While albumin level was significantly lower with increasing FGF-23 level ( $p$ is 0.013 ). Levels of phosphorus, Parathyroid hormone (PTH) and CRP got significantly higher with the increase in (CIMT) ( $p$ is $0.007,0.001$ and 0.004 respectively). FGF 23 levels were significantly correlated with each of CIMT, phosphorus and PTH levels. Correlation was significant between CIMT and age of patient, blood pressure, diabetes, smoking habits, more hemodialysis duration, CRP, higher phosphorus level, FGF23 level, low serum albumin, and higher PTH level. From multiple regression analysis, the most important risk factors correlated to carotid artery atherosclerosis are FGF23, higher phosphorus level, CRP and Diabetes in the order.

Conclusion: FGF23 is a risk factor for the occurrence of vascular atherosclerosis in hemodialysis patients Monitoring of the FGF23 levels may be recommended to predict the possibility of vascular atherosclerosis in those types of patients.
Volume 4 Issue I - 2017

\section{Ibrahim M Salem, Tarek A Ghonemy, Salah F Alsyaed, Hala M Allam, Ali Shendi, Yasser A El Hendy, Amir M El Okely}

Internal Medicine Department, Zagazig university hospital, Egypt

Correspondence: Tarek A Ghonemy, Internal Medicine Department, Nephrology Unit, Zagazig University Hospital, Egypt,Email tarekghonemy@hotmail.com

Received: December 0I, 2016 | Published: February 08, 2017

Keywords: FGF-23, CIMT, CKD, atherosclerosis

Abbreviations: HD, hemodialysis; ESRD, end stage renal disease; CIMT, carotid intima-media thickness; PTH, parathyroid hormone; TC, total cholesterol; HDL-C, high-density lipoprotein cholesterol; ELISA, enzyme-linked immune sorbent assay; HRP, horseradish peroxidase; ECLIA, electro chemi luminescence immunoassay; SD, standard deviation; SE: standard error; ANOVA, analysis of variance; VSMCs, vascular smooth muscles cells

\section{Introduction}

Patients on regular haemodialysis belong to the group of patients with a high prevalence of cardiovascular disease and about half of the deaths in HD patients are attributed to cardiovascular disease. ${ }^{1}$ It is assumed that the atherosclerotic changes in carotid arteries mirror the pathologic events of generalized atherosclerosis. Ultrasound assessment of intimal media thickness and plaque occurrence in carotid arteries were used as an indicator of coronary atherosclerosis in previous studies in the general population as well as in the studies involving patients with ESRD. ${ }^{2}$ Abnormalities in bone metabolism are a prevalent condition in CKD patients and are important determinants of bone and vascular system in this patient population. ${ }^{3}$ Several studies have shown that hyper phosphatemia, increased serum parathyroid hormone (PTH) and low 1,25 (OH) 2D levels are independently associated with increase in total and cardiovascular system mortality in patients with end stage renal disease (ESRD). These observations have raise interest in understanding mineral metabolism regulation and its consequence in patients with ESRD. ${ }^{4}$

Fibroblast Growth Factor-23 (FGF 23) is a novel hormone secreted by osteoblast and it is an important negative regulator of phosphate and vitamin D metabolism. Initially, FGF23 was described as the cause of rare hypophosphatemic syndromes characterized by hypophosphatemia, renal phosphate wasting, low serum level of $1,25(\mathrm{OH}) 2 \mathrm{D} 3$ and osteomalacia or rickets. ${ }^{5}$ FGF23 induce renal phosphate wasting by inhibition of proximal tubular sodium phosphate cotransporter type $2 \mathrm{a}$ and suppressing the renal expression of CYP27B1 resulting in the decrease of $1,25(\mathrm{OH}) 2 \mathrm{D} 3$ synthesis. $^{6}$ FGF23 has been suggested to play a role in vascular calcification in patients on regular HD. ${ }^{7}$ Several studies have indicated that serum levels of FGF23 are elevated in HD patients, and recently, elevated FGF23 concentrations are independently associated with an increased risk of mortality in patients on regular HD. ${ }^{8}$ This work was carried out to evaluate the prevalence of carotid artery atherosclerosis in patients with ESRD on regular haemodialysis and its relation to FGF23 plasma level. 


\section{Subjects and methods}

This cross sectional study has been carried out in Hemodialysis Unit in Zagazig University Hospitals, Egypt over the period from $1 / 1 / 2015$ to $5 / 12 / 2015$.

\section{Subjects}

A total number of 50 patients aged over 18 years and on regular hemodialysis for one or more years were included in this study.

\section{Exclusion criteria}

All subjects were selected to be free from
i. Sign of liver disease
ii. Clinically evident active infection
iii. Autoimmune disease, or known malignancy
iv. Age $<18$

All participants of this study were subjected to a written informed consent.

\section{Methods}

Laboratory investigations: laboratory investigationswere done according to the methods applied in the clinical pathology laboratories of zagazig university hospitals and included Complete blood count (using pentra 80 auto counter), Fasting \& postprandial blood glucose, Kidney functions tests (creatinine \& urea), Liver function tests (AST, ALT, serum pro thrombin, serum albumin, Serum alkaline phosphatase and serum bilirubin), Serum calcium, phosphorous, sodium and potassium done using Auto-analyzer synchron CX5 (Beckman, USA), and Lipid profile: Total cholesterol (TC) was assayed using the enzymatic colorimetric method with cholesterol esterase and cholesterol oxidase. High-density lipoprotein cholesterol (HDL-C) was measured after precipitation of apolipoprotein B- containing lipoproteins with phosphotungstic acid. Triglycerides were assayed using enzymatic colorimetric assay with glycerol phosphate oxidase. The intact FGF-23 enzyme-linked immune sorbent assay (ELISA) and carboxy-terminal FGF-23 ELISA was evaluated (Immutopics, Inc., San Clemente, CA). The intact FGF-23 assay is a sandwich ELISA and consists of a 96-well plate coated with goat anti-human FGF-23 (carboxy-terminal portion) to which sample is added, and a solution of goat anti-human FGF-23 (amino-terminal portion) conjugated to horseradish peroxidase (HRP) for detection. Values are expressed in $\mathrm{pg} / \mathrm{mL}$. Serum Intact PTH concentration was measured with the Elecsys PTH assay (Roche). The Electro Chemi Luminescence Immunoassay (ECLIA) is intended for use on Elecsys and Co base immune assay analyzers.

\section{Radiology investigations}

Duplex scan of the carotid arteries was performed to assess carotid intima-media thickness by high-resolution real-time B mode ultrasonography with a $7.5-\mathrm{MHz}$ linear transducer (SSH 140A Toshiba, Japan).

Statistical analysis: Data were analyzed with SPSS version 16.0 (statistical package for the Social Science, Chicago, IL). The variables were tested for normality and the distribution was normal. Quantitative data were expressed as mean \pm standard deviation (SD) or standard error $(\mathrm{SE}) . \mathrm{SE}=\mathrm{SD} /$ square root of patients number which was used in case of big SD, data were analyzed by independent sample, paired t test and one way analysis of variance (ANOVA). While qualitative data were expressed as number and percentage and were analyzed by Chi square (x2) test. Correlation was done using Pearson correlation test. Risk factors varables which can be related to the incident of carotid intimal thickening (CIMT) were analyzed by logistic regression analysis. $P$ is significant if $<0.05$ at confidence interval $95 \%$ where $\mathrm{b}$ is the $\log$ it coefficient and exp $\mathrm{b}$ is the odds ratio.

\section{Results}

Hemodialysis patients were divided according to FGF-23 levels into 3 Tertiles, tertile 1 included patients with level $<454 \mathrm{RU} / \mathrm{ml}$, tertile 2 included patients with level between 454 to $10230 \mathrm{RU} / \mathrm{ml}$ and tertile 3 which included patients with level $>1023 \mathrm{RU} / \mathrm{ml}$. Demographic characteristics of the studied patients are shown in Table 1 . Statistically significant difference was found between the three groups as regard the duration of hemodialysis $(\mathrm{P}<0.05)$. While no significant changes has been found between the groups regarding other parameters (gender, age, BMI, presence of diabetes and hypertension and smoking habits $(p$ is $0.61,0.29,0.0 .19,0.62$ and 0.41 respectively). The laboratory data, as shown in Table 2, revealed significantly higher serum Phosphorus, LDL, and PTH in patients with tertile 3 (higher FGF-23) ( $p$ 0.005, $0.013,0.02$ and $<0.001$ respectively). While no significant changes in other parameters. Regarding the carotid intima media thickness (CIMT), there was significant increasing in the intimal thickness with higher level of FGF-23 tertile (tertile 3 ) as shown in Table 2.

Table I Demographic distribution of patients according to FGF 23

\begin{tabular}{|c|c|c|c|c|c|}
\hline & $\begin{array}{l}\text { Total characteristics of the } \\
\text { patients(mean) }\end{array}$ & $\begin{array}{l}\text { FGF-23 Tertile I< } \\
454 \mathrm{RU} / \mathrm{ml}\end{array}$ & $\begin{array}{l}\text { FGF-23 Tertile } \\
2454-1023 \mathrm{RU} / \mathrm{ml}\end{array}$ & $\begin{array}{l}\text { FGF-23 Tertile 3> } \\
\text { I023 RU/ml }\end{array}$ & $\mathbf{P}$ \\
\hline Number & 50 & $16(32 \%)$ & $16(32 \%)$ & $18(36 \%)$ & 0.61 \\
\hline Male/Female & $35 / 15$ & $5-\mathrm{Nov}$ & 6-Oct & $14 / 4$ & \\
\hline Age(year) & 43 & $44 \pm 16$ & $43 \pm 12$ & $50 \pm 14$ & 0.29 \\
\hline $\begin{array}{l}\text { Body mass } \\
\text { index(Mean } \pm S D)\end{array}$ & 23.3 & $23 \pm 1.9$ & $24 \pm 1.4$ & $24 \pm 1.2$ & 0.1 \\
\hline HD Duration (Month) & 49 & $38 \pm 9$ & $52 \pm 4$ & $59 \pm 2$ & 0.01 \\
\hline Diabetes (\%) & $20(40 \%)$ & $5(31.25 \%)$ & $8(50 \%)$ & $7(38.8 \%)$ & 0.19 \\
\hline Hypertension (\%) & $33(66 \%)$ & $10(62.5 \%)$ & $13(81.25 \%)$ & $10(55.5 \%)$ & 0.62 \\
\hline Smoking (\%) & $18(36 \%)$ & $6(37.5 \%)$ & $4(25 \%)$ & $8(44.4 \%)$ & $0.4 \mathrm{I}$ \\
\hline
\end{tabular}


Table 2 Laboratory data of patients classified according to FGF 23

\begin{tabular}{|c|c|c|c|c|c|}
\hline & $\begin{array}{l}\text { Total characteristics of } \\
\text { the patients (mean) }\end{array}$ & $\begin{array}{l}\text { FGF-23 Tertile I< } \\
454 \mathrm{RU} / \mathrm{ml}\end{array}$ & $\begin{array}{l}\text { FGF-23 Tertile } \\
\text { 2454-I } 023 \text { RU/ml }\end{array}$ & $\begin{array}{l}\text { FGF-23 Tertile 3> } \\
\text { I } 023 \mathrm{RU} / \mathrm{ml}\end{array}$ & $\mathbf{P}$ \\
\hline $\begin{array}{l}\mathrm{Ca}++(\mathrm{mg} / \mathrm{dl})(\text { Mean } \\
\pm \mathrm{SD})\end{array}$ & $9.4 \pm 0.5$ & $9.1 \pm 0.4$ & $9 \pm 0.6$ & $9.1 \pm 0.7$ & 0.85 \\
\hline $\mathrm{Ph}(\mathrm{mg} / \mathrm{dl})($ Mean $\pm \mathrm{SD})$ & $4.8 \pm 0.7$ & $4.3 \pm 1$ & $4.9 \pm 0.7$ & $5.2 \pm 0.6$ & 0.005 \\
\hline $\begin{array}{l}\text { S Creatinine }(\mathrm{mg} / \mathrm{dl}) \\
(\text { Mean } \pm \mathrm{SD})\end{array}$ & $10.3 \pm 2.6$ & $10.5 \pm 2.8$ & $10.4 \pm 2.4$ & $10 \pm 2.8$ & 0.84 \\
\hline $\begin{array}{l}\text { S Albumin }(g / d l) \text { (Mean } \\
\pm \text { SD) }\end{array}$ & $3.9 \pm 0.4$ & $4.2 \pm 0.6$ & $3.8 \pm 0.6$ & $3.7 \pm 0.2$ & 0.013 \\
\hline $\begin{array}{l}\mathrm{HDL}(\mathrm{mg} / \mathrm{dl})(\text { Mean } \\
\pm \mathrm{SD})\end{array}$ & $42 \pm 18$ & $40 \pm 15$ & $44 \pm 25$ & $42 \pm 15$ & 0.83 \\
\hline $\begin{array}{l}\text { LDL }(m g / d l)(\text { Mean } \\
\pm S D)\end{array}$ & $92 \pm 14$ & $89 \pm 14$ & $87 \pm 17$ & $100 \pm 12$ & 0.02 \\
\hline $\begin{array}{l}\text { Cholesterol }(\mathrm{mg} / \mathrm{dl}) \\
(\text { Mean } \pm \text { SD) }\end{array}$ & $|5| \pm 44$ & $148 \pm 49$ & $|56 \pm 4|$ & $149 \pm 42$ & 0.85 \\
\hline $\begin{array}{l}\text { TG(mg/dl) (Mean } \\
\pm S D)\end{array}$ & $|45.6 \pm 4|$ & $143 \pm 55$ & $|5| \pm 29$ & $143 \pm 40$ & 0.82 \\
\hline $\begin{array}{l}\text { CRP }(\mathrm{mg} / \mathrm{dl})(\text { Mean } \\
\pm \mathrm{SD})\end{array}$ & $22.73 \pm 1.6$ & $23.8 \pm 1.3$ & $21.7 \pm 1.6$ & $22.6 \pm 1.9$ & 0.9 \\
\hline PTH (pg/ml) & $344 \pm 4.6$ & $|2| \pm 4.4$ & $345 \pm 2.6$ & $566 \pm 6.8$ & $<0.001$ \\
\hline \multicolumn{6}{|l|}{$($ Mean $\pm S D)$} \\
\hline CIMT & $0.77 \pm 0.1$ & $0.65 \pm 0.13$ & $0.78 \pm 0.05$ & $0.89 \pm 0.2$ & 0.001 \\
\hline
\end{tabular}

According to the CIMT, patients were divided into other 3 tertiles, 1 with CIMT $<0.7 \mathrm{~mm}, 2$ with CIMT from 0.7 to $1 \mathrm{~mm}$ and 3 with CIMT $>1 \mathrm{~mm}$ and on analysis of the demographic data according to CIMT groups, it was found that there were statistically significant increase in the intimal thickness in patients with more hemodialysis durations, patients with diabetes, hypertension and in smokers ( $p$ $0.001,0.02,0.002$ and 0.039 respectively) see Table 3 . Regarding the laboratory data, the levels of phosphorus, Parathormone and CRP got significantly higher with increasing intimal carotid thickness $(p 0.007$,
0.001 and 0.004 respectively). While albumin level was significantly lower with increasing intimal carotid thickness $(p>0.001)$ See Table 4. FGF 23 levels were significantly positively correlated with each of CIMT, phosphorus and PTH levels (Figure 1). Correlation was significant between CIMT and age of patient, blood pressure, CRP, Phosphorus level, FGF23, low serum albumin, PTH and DM. From multiple regression analysis, the most important risk factor correlated to carotid artery atherosclerosis is FGF23 then phosphorus level then CRP then Diabetes (Table 5).

Table 3 Demographic Distribution of patients according to CIMT

\begin{tabular}{|c|c|c|c|c|c|}
\hline & $\begin{array}{l}\text { Total characteristics of the } \\
\text { patients (mean) }\end{array}$ & $\begin{array}{l}\text { CIMT I }<0.7 \\
\mathrm{~mm}\end{array}$ & $\begin{array}{l}\text { CIMT } 20.7-1 \\
\mathrm{~mm}\end{array}$ & $\begin{array}{l}\text { CIMT 3> I } \\
\mathrm{mm}\end{array}$ & $\mathbf{P}$ \\
\hline Number & 50 & $15(30 \%)$ & $16(32 \%)$ & $19(38 \%)$ & 0.66 \\
\hline Male/ Female & $34 / 16$ & 6-Sep & 4-Dec & $13 / 6$ & \\
\hline Age (Mean $\pm S D)$ & 47 & $43 \pm 12$ & $47 \pm 18$ & $51 \pm 16$ & 0.34 \\
\hline $\begin{array}{l}\text { Body Mass Index(Mean } \\
\pm \text { SD) }\end{array}$ & $23.3 \pm 1.4$ & $22.9 \pm 1.8$ & $23.5 \pm 1.4$ & $23.2 \pm 1.2$ & 0.53 \\
\hline HD duration(month) & $50.3 \pm 9.6$ & $42 \pm 8$ & $51 \pm 12$ & $58 \pm 9$ & $<0.001$ \\
\hline Diabetes (\%) & 20 & $2(33 \%)$ & $7(43.7 \%)$ & I I (57.8\%) & 0.02 \\
\hline Hypertension (\%) & 33 & $6(60 \%)$ & II (62.5\%) & $16(73.6 \%)$ & 0.002 \\
\hline Smoking (\%) & 16 & $2(13.3 \%)$ & $4(25 \%)$ & $10(52.6 \%)$ & 0.039 \\
\hline
\end{tabular}


Table 4 Laboratory data of patients classified according to CIMT

\begin{tabular}{|c|c|c|c|c|c|}
\hline & $\begin{array}{l}\text { Total characteristics of the } \\
\text { patients (mean) }\end{array}$ & $\begin{array}{l}\text { CIMTI I } 0.7 \\
\mathrm{~mm}\end{array}$ & $\begin{array}{l}\text { CIMT20.7 - I } \\
\mathrm{mm}\end{array}$ & $\begin{array}{l}\text { CIMT3>I } \\
\mathrm{mm}\end{array}$ & $\mathbf{P}$ \\
\hline $\mathrm{Ca}++(\mathrm{mg} / \mathrm{dl})$ & $10.9 \pm 0.9$ & $10.7 \pm 1$ & $11.2 \pm 1$ & $\mathrm{II} \pm 0.7$ & 0.3 \\
\hline \multicolumn{6}{|l|}{$($ Mean $\pm S D)$} \\
\hline $\mathrm{Ph}(\mathrm{mg} / \mathrm{dl})($ Mean $\pm \mathrm{SD})$ & $5 \pm 1.3$ & $4.3 \pm 0.9$ & $4.9 \pm 1.1$ & $5.9 \pm 1.9$ & 0.007 \\
\hline $\begin{array}{l}\text { S Creatinine }(\mathrm{mg} / \mathrm{dl})(\text { Mean } \\
\pm \mathrm{SD})\end{array}$ & $10.5 \pm 2.4$ & $10.6 \pm 2$ & $10.5 \pm 2.8$ & $10.4 \pm 2.6$ & 0.97 \\
\hline S Albumin(g/dl) (Mean \pm SD) & $3.8 \pm 0.3$ & $4.1 \pm 0.4$ & $3.6 \pm 0.3$ & $3.7 \pm 0.4$ & $<0.001$ \\
\hline HDL(mg/dl) (Mean \pm SD) & $43 \pm 16$ & $42 \pm 14$ & $43 \pm 16$ & $44 \pm 18$ & 0.93 \\
\hline LDL(mg/dl) (Mean \pm SD) & $87.6 \pm 24$ & $86 \pm 28$ & $87 \pm 21$ & $90 \pm 24$ & 0.88 \\
\hline TG (mg/dl) (Mean \pm SD) & $|48 \pm 4|$ & $146 \pm 50$ & $156 \pm 35$ & $142 \pm 38$ & 0.6 \\
\hline $\begin{array}{l}\text { Cholesterol }(\mathrm{mg} / \mathrm{dl}) \text { (Mean } \\
\pm \mathrm{SD})\end{array}$ & $149.6 \pm 44$ & $15 \mid \pm 46$ & $154 \pm 44$ & $148 \pm 42$ & 0.92 \\
\hline $\begin{array}{l}\text { Intact PTH(ng/dl) (Mean } \\
\pm S D)\end{array}$ & $366 \pm 4.9$ & $173 \pm 5.4$ & $328 \pm 2.4$ & $598 \pm 6.9$ & $<0.001$ \\
\hline CRP (mg/dl) (Mean \pm SD) & $16.6 \pm 1.3$ & $11 \pm 1.2$ & $14 \pm 1.6$ & $25 \pm 1.1$ & 0.004 \\
\hline
\end{tabular}

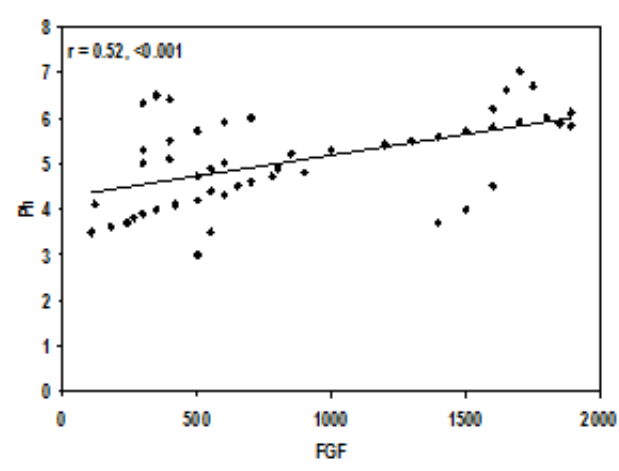

A

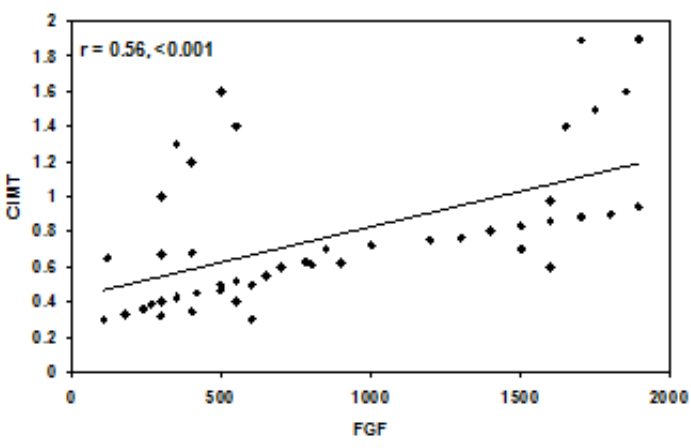

B

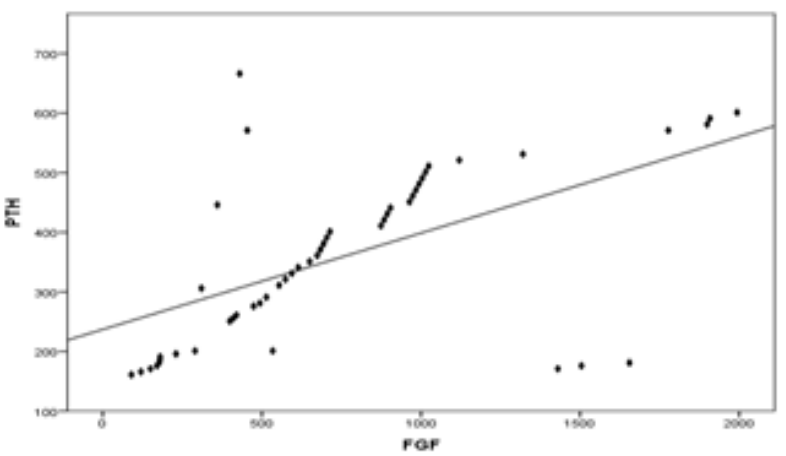

C

Figure I Correlation between FGF and each of CIMT (A), phosphorus (B) and PTH level (C). 
Table 5 Multiple regression analysis of factors associated with CIMT

\begin{tabular}{lllll}
\hline & b & SE & EXP b & P \\
\hline Age & 0.29 & 0.028 & 1.315 & $<0.05$ \\
Blood pressure & 0.295 & 0.029 & 1.241 & $<0.05$ \\
Diabetes & 0.3 & 0.029 & 1.324 & $<0.01$ \\
CRP & 0.34 & $0.030)$ & 1.34 & $<0.01$ \\
Phosphorus & 0.36 & 0.031 & 1.351 & $<0.01$ \\
FGF23 & 0.39 & 0.033 & 1.355 & $<0.001$ \\
\hline
\end{tabular}

\section{Discussion}

Fibroblast growth factor 23 has emerged as a novel important negative regulator of circulating phosphate and 1,25 (OH)2D levels. Fibroblast growth factor 23 levels are progressively elevated in patients with chronic kidney disease and when the patients reach ESRD, FGF-23 levels are often 100- to 1000-times higher than the normal range $(\leq 180 \mathrm{RU} / \mathrm{ml}$ in adults) [9]. Interestingly, increased FGF-23 concentrations have been reported to be independently associated with mortality among patients at the start and on long term HD treatment. ${ }^{10,11}$ Plasma FGF-23 levels emerged as an independent correlate of CIMT in maintenance HD patients in the present work. The results lend further support to the hypothesis that plasma FGF23 level is involved in the high cardiovascular risk of maintenance HD patients and these findings may add evidence to explain the link between elevated FGF-23 levels and mortality in ESRD population. The significant relation between altered mineral metabolism, increased cardiovascular risk, morbidity and mortality in patients with chronic kidney disease raised the possibility whether plasma FGF-23 is independently associated with cardiovascular risk factors. ${ }^{12}$

In this study we found increased level of FGF 23 in the studied patients and this increase was associated with increased carotid intima-media thickness (CIMT) independent of established known risk factors. The significant and positive association of plasma level with CIMT raises the possibility of a specific pathophysiologic effect of FGF-23 on atherosclerosis, distinct from its effects on serum phosphorus and intact parathyroid hormone. Similarly Balci et al., ${ }^{7}$ found that in a study included 128 maintenance HD patients, a strong correlation between high levels of FGF23 and carotid arterial plaque detected by B-mode Doppler ultrasound, independently of established known risk factors in hemodialyzed patients. Also Jean et al., ${ }^{11}$ have showed that FGF23 is linked to peripheral vascular, aortic, and coronary artery calcification in HD patients. Nasrallah et al. ${ }^{13}$ found that Fibroblast growth factor-23 (FGF-23) is independently correlated to aortic calcification in haemodialysis patients. A reasonable explanation for this phenomenon is that FGF-23 may cause thickening and fibrosis of the carotid intima by binding to its receptor. ${ }^{14}$ It is widely accepted that FGFR1 and FGFR4 are receptors for FGF-23, which are present in myocardial cells and the vascular membrane of the coronary vessels and veins. Binding of FGFR1 and FGFR4 are activated upon binding to FGF-23, causing cardiac hypertrophy and fibrosis..$^{15}$

In contrast, Scialla et al. ${ }^{16}$ found that Fibroblast growth factor 23 is not associated with and does not induce arterial calcification. And this can be explained by reduced Klotho expression in the aorta or vascular smooth muscles cells (VSMCs). FGF23 generally requires its cofactor, klotho, for its activity. High levels of FGF23, as well as deficient renal klotho expression and function, are found in CKD patients. It is possible that, in the absence of klotho, increased FGF23 levels exert pro-calcific effects via non-specific low affinity binding to its receptors. ${ }^{17} \mathrm{~A}$ recent study showed that in human arteries, restoration of klotho expression by vitamin D receptor activators could unmask anticalcific effect of FGF23. ${ }^{18}$ These data, even if showing a strong and independent association between FGF23, CVD and hard end points throughout different stages of CKD, are still insufficient to determine the nature of FGF23 as a biomarker or as an effector in vascular calcifications. In this scenario, it remains impossible to accurately discriminate the protective or negative action of FGF23 on vascular calcifications. On the basis of these data, FGF23 may act as a local protector against vascular calcification or it could be (or become) detrimental, especially at the high-extreme concentrations observed in ESRD, by a Klotho-independent activation of fibroblast growth factor receptors along the cardiovascular system. ${ }^{19}$

In our study we found that there was positive correlation between FGF 23 level and phosphorus level. Similarly Mizuiri et al., ${ }^{20}$ reported that high FGF- 23 levels are associated with increased mortality in HD patients and can be caused by hyper phosphatemia. Similarly Wesseling et al., ${ }^{21}$ have linked serum phosphorus concentrations to increased circulating FGF23 levels. In contrast, based on clinical studies, Larsson ${ }^{22}$ stated that the associations among FGF-23, vascular dysfunction, and atherosclerosis were all progressively strengthened in patients with a lower eGFR despite normal phosphate levels, supporting the hypothesis that FGF-23 may provide information about phosphate-related toxicity that cannot be obtained by measurements of serum phosphate levels. In our study we found that there was positive correlation between FGF 23 level and PTH level in studied patients, similarly DeLuca et al., ${ }^{23}$ found that increase FGF23 associated with increased PTH level. In addition, Bai et al., ${ }^{24}$ found that over expression of FGF23 in transgenic mice causes' secondary hyperparathyroidism. Also Galitzer ${ }^{25}$ found that serum levels of both FGF23 and PTH are increased implying resistance of the parathyroid to FGF23, which is due to down regulation of klotho-FGFR1 in the parathyroid. In contrast Ben-Dov et al. [26], found that FGF23 negatively regulates PTH mRNA expression and proteins ecretion in vitro, and that FGF23 suppresses PTH secretion in vivo.

\section{Conclusion}

FGF23 is a risk factor for the occurrence of vascular atherosclerosis in hemodialysis patients. Monitoring of the FGF23 levels may be recommended to predict the possibility of vascular atherosclerosis in those types of patients. In the future, additional investigations are warranted to further clarify the precise mechanisms by which FGF23 contributes to the development of vascular sclerosis.

\section{Limitations}

Our study has some limitations:

I. Small proportion of the patients was a limitation of our investigation.

II. Our study was cross-sectional and we could not compare our findings with a control group. Hence, it is suggested to conduct case-control studies with larger sample sizes to better assess the role of FGF23 in vascular atherosclerosis.

III. We did not record and correlate the effects of medications such as phosphate binders, vitamin $\mathrm{d}$ analogues, lipid lowering medications and the primary causes of renal failure on the effect of FGF23 on vascular atherosclerosis on those patients. 


\section{Compliance and ethical standards}

All procedures performed in studies involving human participants were in accordance with the ethical standards of the institutional and/ or national research committee and with the 1964 Helsinki declaration and its later amendments or comparable ethical standards.

\section{Acknowledgements}

None.

\section{Conflicts of interest}

The author declares there is no conflict of interest.

\section{References}

1. Sarnak MJ, Levey AS, Schoolwerth AC, et al. Kidney disease as a risk factor for development of cardiovascular disease: a statement from the American Heart Association Councils on Kidney in Cardiovascular Disease, High Blood Pressure Research, Clinical Cardiology, and Epidemiology and Prevention. Circulation.12003;08(17):2154-2169.

2. Savage T, Clarke AL, Giles M, et al. Calcified plaque is common in the carotid and femoral arteries of dialysis patients without clinical vascular disease. Nephrol Dial Transplant. 1998;13(8):2004-2012.

3. Slinin Y, Foley RN, Collins AJ. Calcium, phosphorus, parathyroid hormone, and cardiovascular disease in haemodialysis patients: The USRDS waves 1.3 and 4 study. J AM Soc Nephrol. 2005;16(6):17881793.

4. Young EW, Albert JM, Satayathum S, et al. Predictors and consequences of altered mineral metabolism: the Dialysis Outcomes and Practice Patterns Study. Kidney Int. 2005;67(3):1179-1187.

5. White KE, Cabral JM, Davis SI, et al. Mutations that cause osteoglophonic dysplasia define novel roles for FGFR1 in bone elongation. Am J Hum Genet. 2005;76(2):361-367.

6. Saito H, Kusano K, Kinosaki M, et al. Human fibroblast growth factor-23 mutants suppress $\mathrm{Na}+$ - dependent phosphate co-transport activity and 1 alpha, 25- dihydroxy vitamin D3 production. J Biol Chem. 2003;278(4):2206-2211.

7. Balci M, Kirkpantur A, Gulbay M, et al. Plasma fibroblast growth factor-23 levels are independently associated with carotid artery atherosclerosis in maintenance hemodialysis patients. Hemodial Int. 2010;14(4):425-432.

8. Imanishi Y, Inaba M, Nakatsuka K, et al. FGF-23 in patients with endstage renal disease on hemodialysis. Kidney Int. 2004;65(5):1943-1946.

9. Gutierrez O, Isakova T, Rhee E, et al. Fibroast growth factor 23 mitigates hyperphosphatemia but accentuates calcitriol deficiency in chronic kidney disease. J Am Soc Nephrol. 2005;16(7):2205-2215.

10. Gutierrez OM, Mannstadt M, Isakova T, et al. Fibroblast growth factor 23 and mortality among patients undergoing hemodialysis. N Engl J Med. 2008;359(6):584-592.

11. Jean G, Terrat JC, Vanel T, et al. High levels of serum fibroblast growth factor (FGF)-23 are associated with increased mortality in long haemodialysis patients. Nephrol Dial Transplant. 2009;24(9):2792-2796.

12. Block GA, Klassen PS, Lazarus JM, et al. Mineral metabolism, mortality, and morbidity in maintenance hemodialysis. $J$ Am Soc Nephrol. 2004;15(8):2208-2218.

13. Nasrallah MM, El-Shehaby AR, Salem MM, et al. Fibroblast growth factor- 23 (FGF-23) is independently correlated to aortic calcification in haemodialysis patients. Nephrol Dial Transplant. 2010;25(8):2679-2685.

14. Kendrick J, Cheung AK, Kaufman JS, et al. FGF-23 associates with death, cardiovascular events, and initiation of chronic dialysis. J Am Soc Nephrol. 2011;22(10):1913-1922.

15. Gutierrez OM, Januzzi JL, Isakova T, et al. Fibroblast growth factor 23 and left ventricular hypertrophy in chronic kidney disease. Circulation. 2009;119(19):2545-2552.

16. Scialla JJ, Lau WL, Reilly MP, et al. Fibroblast growth factor 23 is not associated with and does not induce arterial calcification. Kidney Int 2011;83(6):1159-1168.

17. Urakawa I, Yamazaki Y, Shimada T, et al. Klotho converts canonical FGF receptor into a specific receptor for FGF23. Nature. 2006;444(7120):770 774.

18. Lim K, Lu TS, Molostvov G, et al. Vascular Klotho deficiency potentiates the development of human artery calcification and mediates resistance to fibroblast growth factor 23. Circulation. 2002;125(18):2243-2255.

19. Razzaque MS. FGF23-mediated regulation of systemic phosphate homeostasis: is Klotho an essential player? Am J Physiol Renal Physiol. 2009;296(3):F470-F476.

20. Mizuiri S, Nishizawa Y, Yamashita K, et al. Lower serum fibroblast growth factor-23 levels may suggest malnutrition in maintenance haemodialysis patients. Nephrology (Carlton). 2014;19(9):568-573.

21. Wesseling-Perry K, Pereira RC, Sahney S, et al. Calcitriol and doxercalciferol are equivalent in controlling bone turnover, suppressing parathyroid hormone, and increasing fibroblast growth factor-23 in secondary hyperparathyroidism. Kidney Int. 2011;79(1):112-119.

22. Larsson TE. The role of FGF-23 in CKD-MBD and cardiovascular disease: Friend or foe? Nephrol Dial Transplant. 2010;25(5):1376-1381.

23. DeLuca S, Sitara D, Kang K, et al. Amelioration of the premature ageing-like features of Fgf-23 knockout mice by genetically restoring the systemic actions of FGF-23. J Pathol. 2008;216(3):215-255.

24. Bai X, Miao D, Li J, et al. Transgenic mice overexpressing human fibroblast growth factor 23 (R176Q) delineate a putative role for parathyroid hormone in renal phosphate wasting disorders. Endocrinology. 2004;145(11):5269-5279.

25. Galitzer H, Ben-Dov IZ, Silver J, et al. Parathyroid cell resistance to fibroblast growth factor 23 in secondary hyperparathyroidism of chronic kidney disease. Kidney Int. 2010;77(3):211-218.

26. Ben-Dov IZ, Galitzer H, Lavi-Moshayoff V, et al. The parathyroid is a target organ for FGF23 in rats. J Clin Invest. 2007;117(12):4003-4008. 